\title{
Recurrent Pleural Malignant Mesothelioma
}

National Cancer Institute

\section{Source}

National Cancer Institute. Recurrent Pleural Malignant Mesothelioma. NCI Thesaurus.

Code C8707.

The reemergence of pleural malignant mesothelioma after a period of remission. 